\title{
VIVENDO E NARRANDO O “SER PROFESSORA" DA EDUCAÇÃO INFANTIL: INCURSÕES DE FRANCISCA
}

\author{
Sílvia Adriana Rodrigues ${ }^{1}$, Andreia Guilhen Pinto ${ }^{2}$ \\ ${ }^{1}$ Doutora em Educação pela Universidade Estadual Paulista Júlio de Mesquita Filho - UNESP, Câmpus de Presidente \\ Prudente, SP. Professora Adjunta da Universidade Federal do Mato Grosso do Sul, atuando na Graduação e Pós- \\ Graduação em Educação no Campus de Três Lagoas e no Programa de Pós-Graduação em Educação do Campus do \\ Pantanal, Corumbá, MS. ORCID iD: https://orcid.org/0000-0003-1249-3976. E-mail: silvia.rodrigues@ufms.br \\ ${ }^{2}$ Mestra em Educação pela Universidade Estadual Paulista Júlio de Mesquita Filho - UNESP, Câmpus de Presidente \\ Prudente, SP, com bolsa da Fundação de Amparo à Pesquisa do Estado de São Paulo (FAPESP). Atualmente, é \\ professora de Educação Infantil na Prefeitura Municipal de Presidente Prudente, SP. ORCID iD: https://orcid.org/0000- \\ 0001-8906-4892. E-mail: andreiaguilhenp@gmail.com
}

\section{RESUMO}

A discussão ora apresentada é um recorte de uma investigação coletiva, em andamento, que objetiva compreender os caminhos de constituição da profissionalidade e identidade docente a partir de narrativas escritas por professora(e)s da Educação Básica e Ensino Superior. Assim, nos limites desse artigo são trazidas as reflexões desencadeadas pela história de uma professora atuante na Educação Infantil. A leitura dos escritos de nossa narradora, pautada no dialogismo e na alteridade, nos levou a (re)afirmar o potencial formativo e reflexivo das narrativas não só para quem narra, mas também para quem as lê; bem como, o quanto os caminhos de construção/constituição da docência - mesmo sendo particulares e singulares recebem influência de elementos plurais e coletivos do contexto sócio-cultural (concreto e subjetivo) em que os sujeitos estão inseridos.

Palavras-chave: Identidade para a docência. Saberes da profissão. Narrativa.

\section{LIVING AND NARRATING THE "BEING A TEACHER" IN CHILDHOOD EDUCATION: FRANCISCA INCURSIONS}

\begin{abstract}
The discussion now presented is an excerpt from a collective investigation, in progress, which aims to understand the ways of constituting professionalism and teaching identity from narratives written by teachers of Basic Education and Higher Education. Thus, within the limits of this article, the reflections triggered by the story of an active teacher in Early Childhood Education are brought up. Reading the writings, based on dialogism and otherness, led us to affirm the formative and reflective potential of the narratives not only for those who narrate, but also for those who read them; as well as the extent to which the teaching construction/constitution paths - even being singular - are influenced by plural and collective elements of the socio-cultural context (concrete and subjective) that the subjects are inserted in.
\end{abstract}

Keywords: Identity for teaching. Knowledge of the profession. Narrative.

\section{VIVIR Y NARRAR EL “SER MAESTRO” EN EDUCACIÓN INFANTIL: INCURSIONES FRANCISCA}

\section{RESUMEN}

La discusión aquí presentada es un extracto de una investigación colectiva, en proceso, que tiene como objetivo comprender las formas de constituir la profesionalidad y la identidad docente a partir de narrativas escritas por docentes de Educación Básica y Superior. Así, dentro de los límites de este artículo, se plantean las reflexiones que suscita la historia de una docente activa en Educación Infantil. La lectura de los escritos de nuestro narrador, desde el dialogismo y la otredad, nos llevó a afirmar el potencial formativo y reflexivo de las narrativas no solo para quienes narran, sino también para quienes las leen; así como en la medida en que los caminos de construcción/constitución docente, aun siendo privados y singulares, están 
influenciados por elementos plurales y colectivos del contexto sociocultural (concreto y subjetivo) en el que se insertan los sujetos.

Palabras clave: Identidad para la docencia; Conocimiento de la profesión; Narrativa.

O cronista que narra os acontecimentos, sem distinguir entre os grandes e os pequenos, leva em conta a verdade de que nada do que um dia aconteceu pode ser considerado perdido na história. (BENJAMIN, 1987).

\section{INTRODUÇÃO}

Movidas pelo espírito benjaminiano ilustrado na epígrafe é que nos empenhamos na escrita do presente artigo cujo movimento busca, de certa forma, uma leitura da profissão docente, acolhendo no presente as experiências do passado narradas em cartas escritas em resposta ao chamamento do Grupo de Pesquisa do qual fazemos parte.

Tratamos então de evidenciar, dentro dos limites dessa discussão, um recorte do estudo em andamento desde o ano de 2018, realizado de forma coletiva, com o objetivo maior de "[...] compreender as características constituintes da identidade e profissionalidade docente ao longo da carreira, envolvendo aspectos da formação e do desenvolvimento profissional em diferentes níveis, modalidades de ensino e contextos [...]" (RODRIGUES; GOMES, 2018, p. 124).

A investigação em questão, com caráter qualitativo, trilha os caminhos da pesquisa narrativa, tendo como participantes professora(e)s atuantes na Educação Básica e no Ensino Superior; e, como estratégia/instrumento para recolha das informações, a carta,

[...] por entendermos que ela valoriza as singularidades do escritor, além de se configurar como uma possibilidade de conversa realizada a dois, de forma peculiar [...] A carta convida as pessoas a responderem contando sua trajetória formativa envolvendo aspectos de suas vivências como alunos da educação básica, da formação inicial/continuada para o magistério e de sua trajetória profissional. (GOMES; RODRIGUES; SOUZA, 2019, p. 3).

São essas algumas das premissas que moveram o envio de cartas a profissionais docentes, que previamente aceitaram o convite para colaborar com nosso estudo, nos respondendo com a narrativa, em primeira pessoa, de sua trajetória formativa, pessoal e profissional. Solicitamos a(o)s educadora(e)s que revisitassem os momentos significativos de suas experiências na educação básica, bem como na formação inicial e continuada para atuação no magistério, e, ainda, suas vivências profissionais. A devolutiva de nosso pedido/convite resultou, até o momento, no recebimento de 29 cartasresposta, que estão em processo de leitura e discussão, realizadas nas reuniões periódicas de nosso Grupo de Pesquisa.

Consideramos importante salientar que a etapa de leitura e análise das cartas tem se realizado orientada pelo esforço de "[...] evidenciar as particularidades e a complexidade de cada narrativa, levando em consideração a realidade concreta de cada participante [...]" (GOMES; RODRIGUES; SOUZA, 2019, p. 3), bem como se pautado, "[...] prioritariamente, pelo que emerge do conteúdo das narrativas [...] buscando assim respeitar e manter em evidência a voz do(a) narrador(a)[...]" (RODRIGUES, et al., 2020, s. p.). Não obstante, definimos alguns eixos norteadores de nossa leitura, para o direcionamento do olhar, buscando evitar grandes dispersões ou inflexões, uma vez que esta é uma tarefa, que salientamos novamente, tem se realizado de forma coletiva. Nesta direção, [...] com o propósito de
compreensão e não de
explicação das
informações obtidas,
procuramos identificar, no
conteúdo das narrativas,
elementos que sinalizem
sobre os sentidos dados à
sua trajetória de
formação, trajetória
profissional, motivação
para ingresso na profissão,
identificação com a
docência, imagens da 
profissão docente, além das memórias mais significativas; itens que são tomados como norteadores básicos da leitura das cartas e não como unidades comparativas de análise. (GOMES; RODRIGUES; SOUZA, 2019, p. 3).

Na dinâmica descrita, merece também destaque $\mathrm{o}$ intento de ter como norte das reflexões os sentidos que emergem em cada uma das narrativas; isto porque consideramos ser necessário evidenciar as distintas vozes presentes numa pesquisa narrativa: a do narrador - sujeito da pesquisa - informante e protagonista da história narrada; e, a do pesquisador - ouvinte interlocutor e também narrador, sem que, na apresentação dos achados do estudo, uma não sobrepuje ou subvalorize a(s) outra(s) ${ }^{1}$. (CLANDININ; CONELLY, 2011).

Considerar as vozes que compõem todo e qualquer discurso nos coloca frente à tarefa de transitar não só no terreno das descobertas, revelações e tomada de conhecimento que usualmente as informações de qualquer investigação permitem, mas também "das produções de sentido entre o eu e o outro" que nos convoca, necessária e obrigatoriamente, a assumir uma postura dialógica, exotópica e alteritária na leitura das histórias que nos são, generosamente, ofertadas por diferentes professora(e)s (BAKHTIN, 1997). Na busca por construir uma percepção que envolve "ver-se" e "completar-se" (concatenando os diferentes olhares, como já assinalado), impõe-se a tarefa de:

[...] identificar-me com o outro e ver o mundo através de seu sistema de valores, tal como ele vê; devo colocar-me em seu lugar, e depois, de volta ao meu lugar, contemplar seu horizonte com tudo o que se descobre do lugar que ocupo fora dele; devo emoldurá-lo, criar-lhe um

\footnotetext{
${ }^{1}$ Consideramos oportuno esclarecer que adotamos o procedimento de fazer pequenos ajustes (ortográficos e/ou gramaticais) nas escritas das narrativas recebidas no sentido de preservar a imagem de nossa(o)s protagonistas. São acertos que não alteram os sentidos dos "ditos"; maneirismos, expressões típicas da oralidade e/ou deslizes de flexão gramatical são suprimidas, dando apenas "polimento" à escrita.
}

ambiente que 0 acabe, mediante o excedente de minha visão, de meu saber, de meu desejo e de meu sentimento.

(BAKHTIN, 1997, p. 45).

Tomando esses e outros desafios como provocações para a produção do conhecimento, temos estado imersas nas memórias de muita(o)s profissionais da educação, educadora(e)s que nos permitiram adentrar em suas histórias como uma forma de conhecer mais sobre os caminhos particulares e singulares de construção/constituição da docência que trazem pistas valiosas para a construção de entendimentos sobre os meandros da profissionalização docente. Assim, o que ora apresentamos são elementos subtraídos da carta da participante, aqui nomeada Francisca, professora da Educação Infantil de uma cidade do interior do estado do Mato Grosso do Sul.

\section{SOBRE TORNAR-SE E SER PROFESSORA DA EDUCAÇÃO INFANTIL: OS DIZERES DE FRANCISCA}

Importante iniciar esse subtítulo com a (re)afirmação que temos como pressuposto de que pensar em profissionalidade implica, necessariamente tratar de subjetividades; neste sentido, todas as experiências vividas (laboral, social, existencial) constituem espaços de aprendizagem e valiosas bases de reflexão, de fontes pertinentes para favorecer o (re)conhecimento dos processos de formação identitária da(o)s professora(e)s na atualidade.

A professora escolhida para ser a protagonista de nossa discussão, a qual chamaremos de Francisca ${ }^{2}$, tinha 50 anos no momento da escrita da carta; nordestina, natural do Crato-CE, inicia seu relato deixando claro sua origem humilde e o pensamento dos pais com relação ao "valor da educação"

[...] meus pais que
possuíam aquele velho
pensamento de que a
única herança que poderia
deixar para os filhos era a
educação, que ladrão
nenhum poderia roubar,

\footnotetext{
${ }^{2}$ Nome atribuído pelas pesquisadoras para preservar a identidade da professora.

${ }^{3}$ Para permitir uma diferenciação entre as citações das obras que servem de fundamentação teórica e os recortes da narrativa trazidos ao longo do texto, subvertemos as normas da ABNT e os trechos da narrativa estão destacados com itálico.
} 
conseguiram bolsa de estudo para que os filhos pudessem estudar em escolas particulares e foi assim que pude transitar nos dois lados da escola [...]. (Excertos da carta de Francisca, 2018).

Entendemos que para uma parcela significativa da população é forte a representação do "valor do estudo"; que ele permite a aquisição de um bem intransferível e inalienável. Focada neste ponto, Francisca nos relata que estudou em escolas pública, filantrópica e privada; e ainda, que sua relação com a escola não era das melhores...

[...] eu era tímida, atrasada nos estudos, repeti o primeiro ano por não saber ler, era muito dependente da minha prima que estudou comigo desde então. Pra mim a melhor hora era o recreio, que brincava, comia o lanche, voltar pra sala de aula era uma tortura. Adorava os dias que não tínhamos aulas. Durante muito tempo era assim, a professora chegou a perguntar para minha mãe se eu era muda, mas a minha mãe disse que não, em casa eu falava muito bem. (Excertos da carta de Francisca, 2018, grifos nossos).

Chama atenção o fato de Francisca permear seu relato com avaliações negativas sobre si; de igual maneira é interessante como não transparece em seus dizeres a atribuição de responsabilidade direta à escola, de forma geral mesmo que se refira a ela, ao seu desconforto com o ambiente escolar... Há um lugar específico para isso: a sala de aula, pois fora dela as experiências são descritas como prazerosas.

E suas experiências negativas com a sala de aula se estendem durante toda a educação básica, agora com um destaque significativo para a disciplina de Matemática:

Eu era péssima em Matemática, isso eu trago comigo até hoje, a minha professora era muito depressiva, cara fechada o tempo todo, ela nos chamava até sua mesa e pedia para colocarmos as mãos em cima da mesa para não contarmos nos dedos quando tomasse a tabuada. $\mathrm{Na}$ verdade, nunca aprendi a tabuada, embora decorasse toda vez que precisei.

[...] No Ensino Médio tive um professor de Matemática muito brincalhão, mas a minha relação com a Matemática continuou péssima. (Excerto da carta de Francisca, 2018).

O trecho selecionado evidencia dois recorrentes estereótipos estreitamente relacionados: "a Matemática megera", e a "professora megera de Matemática". As impressões guardadas na memória de nossa narradora de uma imagem negativa de uma professora de um conteúdo específico, descrita com detalhes, e que consideramos não ser uma percepção isolada, nos levam a retomar o entendimento de Ferraroti (1988, p. 26) de que "[...] nós somos, se todo o indivíduo é, a reapropriação singular do universal social e histórico que o rodeia [...]"; bem como que "[c]ada indivíduo não totaliza diretamente uma sociedade global, mas totaliza-a pela mediação do seu contexto social imediato, pelos grupos restritos de que faz parte, pois estes grupos são por sua vez agentes sociais ativos que totalizam o seu contexto, etc." ${ }^{\prime 4}$.

Assim como Francisca, é comum entre professores e estudantes de cursos de Pedagogia e/ou Magistério (notadamente localizados como profissionais da Educação Infantil e do Ensino Fundamental), uma aversão ou sentimentos negativos nutridos em relação à disciplina de Matemática; tal recorrência é apontada, entre outros, por Nacarato, Mengali e Passos (2011, p. 23), que também sinalizam que não raro se apresentam "[...] marcas profundas de sentimentos negativos em relação a essa disciplina, as quais implicam, muitas vezes, bloqueios para aprender e para ensinar", como se nota no relato de nossa protagonista. A situação é tão impactante e desgastante para

\footnotetext{
${ }^{4}$ (Ibidem, p. 31)
} 
Francisca, que ela aventa parar os estudos, o que não se concretiza devido à coibição da mãe. É este o contexto que vai delimitando o caminho que faz Francisca chegar ao Magistério:

Queria parar de estudar, mas a minha mãe não deixou, aí eu descobri que no curso Magistério não tinha Matemática, nada de equações complexas, era a didática da Matemática, bem simples, foi aí que tive a feliz ideia de cursar o Magistério, nem achei que iria me identificar tanto. Fiquei de fato muito encantada. A minha formação para o magistério foi em 1986, teve quatro anos de duração, tudo era muito atraente [...]. (Excerto da carta de Francisca, 2018, grifo nosso).

A entrada de Francisca no campo do Magistério não deixa de ser emblemática, pois não há uma motivação clara atrelada à identificação com o ofício de ensinar; tampouco a recorrente justificativa de que este é um campo que permite relativa facilidade de entrada no mercado de trabalho. Trata-se de "uma fuga da Matemática", desencadeada por uma percepção simplista da didática da matemática. Esta concepção é fomentada pelo contexto histórico em que Francisca cursou o magistério. De acordo com Nacarato, Mengali e Passos (2011), embora a década de 1980 seja marcada pela elaboração das Propostas Curriculares, os cursos de Magistério em funcionamento, ainda que tivessem propostas pedagógicas interessantes, tinham brechas em relação ao ensino de matemática que visava à formação das futuras professoras para atuação na - hoje reconhecida como - educação básica, pois:

[...] na maioria deles não
havia educadores
matemáticos que
trabalhassem com as
disciplinas voltadas à
metodologia de ensino de
matemática-muitos eram
pedagogos, sem formação
específica. Decorria daí
muitas vezes, uma
formação centrada em
processos metodológicos,

desconsiderando

OS

fundamentos

da

matemática. (NACARATO; MENGALI; PASSOS, 2011, p. 17-18).

No entanto, 0 atalho tomado por Francisca, conforme grifamos no trecho anterior, Ihe surpreende e desperta um entusiasmo pela docência até então não aventado; os conteúdos "não matemáticos" lhe apresentam o universo do ensino e um roteiro de aprendizagens prazerosas:

[...] tudo era muito atraente, os cursos de métodos de alfabetização, como 'a casinha feliz, o vespertino', os métodos de ensino, as estratégias que ensaiávamos para atingir os alunos, teatro, brinquedos e brincadeiras, poesias, histórias, etc. eu gostava de aprender $e$ ensinar. (Excertos da carta de Francisca, 2018, grifos nossos).

A criança tímida, atrasada nos estudos, que não sabia ler, tornava-se uma mulher, futura professora, capaz, não apenas de aprender, mas também de ensinar. Assim, a narrativa de Francisca sobre sua vivência escolar até aqui se apresenta em dois atos: a trajetória de formação na educação Básica e a de formação profissional para atuação no Magistério. Se a sala de aula da educação básica esteve marcada por desapontamentos, seja com a professora pouco simpática ou pela disciplina a qual nunca simpatizou, que potencializaram aspectos não atraentes de sua personalidade como a timidez e a insegurança, o Magistério, ao contrário, proporciona a construção de saberes diversos e a constituição da identidade profissional de nossa protagonista; ou seja, inicia-se o processo de, mais claramente, tornar-se professora...

Francisca relata que no ano seguinte ao ingresso do Magistério tem início a sua vida profissional como docente: "[n]o ano de 1987 comecei a trabalhar como professora de Educação Infantil na escolinha do Balão Mágico, no ano seguinte trabalhei no colégio Pequeno Príncipe, onde lecionei por 5 anos no pré-escola" (Excerto de Francisca).

Nossa narradora trilha os mesmos passos de muito(a)s professor(a)s: conduzir uma jornada 
dupla composta pelo trabalho e a formação profissional inicial; e, sobre esta situação é possivel tecer considerações em duas direções: uma que a percebe como negativa, uma vez que trabalhar e concomitantemente estudar pode ser cansativo e atrapalhar o segundo processo. A outra, como positiva, no sentido que as vivências paralelas podem colaborar para a constituição da identidade profissional mais sólida, pois tem o potencial de permitir reflexões cotidianas sobre a prática docente através das próprias experiências profissionais pautadas nos saberes em construção como estudante. Nessa direção, Francisca evidencia em sua narrativa como os aprendizados do curso eram utilizados em sua prática profissional:

Gostava muito da
proposta da Emilia
Ferreiro, Piaget, e por isso
focava muito a proposta
construtivista no meu
trabalho, embora ficasse
ainda muito apegada aos
exercícios instrucionais,
como todos os professores
da minha época e acho
que acontece até hoje,
havia uma ansiedade
muito grande de que as
crianças fossem
alfabetizadas, então
desde cedo já
começávamos a aplicar os
métodos de alfabetização,
que na época era 'A
Casinha Feliz', embora já
estivesse deixando a
cartilha de lado por
considerar arcaica [...]
(Excerto da carta de
Francisca, 2018, grifos
nossos).

A proposta construtivista de alfabetização foi amplamente divulgada no Brasil no início da década de 1980 , e essa vertente - e notadamente o trabalho de Emília Ferreiro - foi a grande influenciadora dos debates, propostas de formação e políticas de alfabetização no Brasil até os anos 2000 - quando começam a entrar em evidência as discussões da teoria sócio-histórica sobre a questão -, fato que explica a opção de nossa protagonista, naquele momento, pelos autores citados em seu relato.

No entanto, o que mais nos provoca no excerto destacado diz respeito ao trecho grifado:
"[...] ansiedade muito grande de que as crianças fossem alfabetizadas [...]" (Excertos de Francisca). Cabe então registrar o nosso desconforto com o fato exposto na narrativa que ainda se faz presente no contexto da Educação Infantil: a preocupação em antecipar nesse nível os conteúdos e processos que são próprios do Ensino Fundamental; uma ideia amplamente aceita e defendida por muitos pais, professores, pesquisadores e atualmente até pelos responsáveis pela elaboração de políticas públicas educacionais. Postura com a qual não concordamos, uma vez que entendemos a educação infantil como:

[...] espaço de constante construção de conhecimentos; um processo realizado a partir do contato com múltiplas linguagens: musical, plástica, teatral, gestual, corporal, de leitura e escrita, de matemática, etc., sem a supervalorização de nenhuma em detrimento das outras, favorecendo aprendizagens e $\mathrm{o}$ desenvolvimento, bem como a ampliação das formas infantis de leitura e interpretação do mundo. (RODRIGUES; SAMBUGARI, 2018, p. 689).

Ressaltamos que nossa opinião se assenta na defesa de que o trabalho com a linguagem escrita na Educação Infantil está intimamente ligado à percepção de qual é a função social desta última, quer seja: a socialização em sentido amplo - evidenciada de forma bastante clara nos documentos legais brasileiros que normatizam este nível de ensino (RODRIGUES; SAMBUGARI, 2018); logo, alfabetizar não deve figurar como prioridade na organização das práticas pedagógicas. Tomando como referência, primeiro a Lei de Diretrizes e Bases da Educação Nacional $n^{\circ}$. 9.394/96 - que reconhece este nível de ensino como primeira etapa da educação básica - o propósito da Educação Infantil (creche e pré-escola) é promover o desenvolvimento integral e integrado das crianças pequenas "[...] em seus aspectos físico, psicológico, intelectual e social [...]" (BRASIL, 1996, art. 29). No que diz respeito às Diretrizes Curriculares Nacionais para Educação 
Infantil - DCNEI, documento máximo a ser observado na organização pedagógica do nível educacional em questão, as práticas cotidianas das instituições devem garantir às crianças "[...] acesso a processos de apropriação, renovação e articulação de conhecimentos e aprendizagens de diferentes linguagens, assim como o direito à proteção, à saúde, à liberdade, à confiança, ao respeito, à dignidade, à brincadeira, à convivência e à interação com outras crianças". (BRASIL, 2010, p. 18).

Nosso entendimento é, em grande medida, o mesmo de Francisca atualmente; no entanto, chegar a esse ponto, como nos mostra seu relato, foi uma construção, desencadeada por diferentes processos formativos, que começaram a ter impacto quando nossa narradora se depara com as contradições entre a sua vivência como aprendiz da escola básica e as práticas agora exigidas dela como educadora que a desafiavam a deter outros saberes.

$$
\begin{aligned}
& \text { [...] tínhamos as } \\
& \text { formações que nos traziam } \\
& \text { várias informações de } \\
& \text { como conduzir o trabalho } \\
& \text { com os pequeninos. } \\
& \text { Os trabalhos deveriam ser } \\
& \text { desenvolvidos a partir do } \\
& \text { movimento do corpo, com } \\
& \text { atividades que } \\
& \text { explorassem os sentidos, o } \\
& \text { desenho feito pela própria } \\
& \text { criança, que valorizassem } \\
& \text { as histórias infantis, etc., } \\
& \text { isso me levou a pensar } \\
& \text { muito na minha prática } \\
& \text { pedagógica, por vir de } \\
& \text { uma formação tradicional } \\
& \text { e arcaica como foi a } \\
& \text { minha, era difícil de me } \\
& \text { desvencilhar destas velhas } \\
& \text { práticas, pois a pedagogia } \\
& \text { do brincar ainda é até hoje } \\
& \text { vista com um certo } \\
& \text { preconceito pela } \\
& \text { comunidade escolar, que } \\
& \text { muitas vezes acreditam } \\
& \text { que a criança vai pra } \\
& \text { escola para estudar, tal } \\
& \text { como acontece nos anos } \\
& \text { seguintes do Ensino } \\
& \text { Fundamental. (Excertos da } \\
& \text { carta de Francisca, 2018). }
\end{aligned}
$$

A formação em nível superior, que irá acontecer 11 anos após o ingresso de Francisca na profissão consolida sua identificação com a profissão e na carreira docente.

Só no ano de 1998 que eu fui fazer o curso de pedagogia na UFMS campus do Pantanal, tendo concluído em 2001, pra mim foi muito importante terminar o curso superior [...] o que me ajudou tanto como formação humana, como profissional, aprendi a superar os desafios de educar [...] e melhorou muito minha prática pedagógica o que me levou a galgar mais alguns degraus na minha carreira, entrei pra prefeitura de Corumbá no ano de 2004, na qual trabalho até hoje [...] (Excerto da carta de Francisca, 2018).

Cremos que nossa protagonista denota preocupar-se com a formação, que valora este como um movimento que deve ser contínuo e se constitui como indispensável para o exercício da sua profissão... "[...] tenho feito vários cursos de formação na área e fiz duas pós-graduações: uma em Educação Infantil e outra em Psicopedagogia. Atualmente sou aluna de Mestrado na Universidade Federal do Mato Grosso do Sul, no município de Corumbá [...]" (Excerto da carta de Francisca, 2018).

Tardif e Lessard (1999, p. 35) já nos ensinaram que: "[a] docência é um trabalho cujo objeto não é constituído de matéria inerte ou de símbolos, mas de relações humanas com pessoas capazes de iniciativa e dotadas de uma certa capacidade de resistir ou de participar da ação dos professores"; tal apontamento é ainda mais significativo quando nos referimos ao trabalho junto as crianças da Educação Infantil, uma vez que espera-se do professor da Educação Infantil que este assuma - de forma integral - a condição de adulto capaz de compreender a condição "infantil" dos aprendizes com os quais lida, bem como as razões disto para melhor selecionar estratégias de ação adequadas aos diferentes tempos, espaços e sujeitos cotidianos.

Nessa direção tem-se o esclarecimento de Nascimento (1999, p. 101) de que "[...] por lei, a Educação Infantil é um nível de ensino e isto traz consequências para o perfil do profissional 
que atua neste campo". Assim, "[um]a proposta pedagógica e curricular se efetiva [...] através de atividades realizadas por crianças e adultos em interação [...] espera-se que os adultos facilitem e promovam os processos de interação ativa da criança com pessoas e as coisas [...]" (GUIMARÃES; GARMS, 2013, p. 20). Tais premissas levam a conclusão de que é necessária e imprescindível uma ação intencional de sujeitos com formação profissional nas creches e préescolas, pois "[n]ão se pode aceitar amadorismo num trabalho cujo fim é a formação de pessoas" (ANGOTTI, 2006, p. 102).

$$
\text { Também é }
$$

importante $\quad 0$

comprometimento com as tarefas da docência e com o cumprimento da função social da educação infantil - elementos que são evidenciados no relato de Francisca; é transparente sua satisfação com o exercício profissional, e a realização pessoal por atuar no espaço da Educação Infantil.

[...] tenho 20 anos de trabalho com a educação infantil, o que é muito gratificante, pois pra mim é muito encantador ver $o$ desenvolvimento das crianças, do prazer que procuro resgatar pelo aprender dentro da instituição de educação, procuro na minha prática do dia a dia observar como eles aprendem pelas curiosidades e ludicidade $e$ uso isso como fio condutor do meu trabalho, tenho desenvolvido alguns projetos, mas sempre me esbarro na falta da aplicação de políticas públicas que coloquem em prática o que hoje se constitui em direito legal da criança, que são materiais, e espaços adequados de ensino para elas, e outros. (Excerto da carta de Francisca, 2018).

Esse excerto - e quiçá toda a narrativa de Francisca - também nos leva a ponderar duas questões: a primeira é que ele coloca nosso estudo na posição de corroborar o apontamento de Oliveira, Ferreira e Barros $(2011$, p. 6) de que a formação para a docência é um "[...] processo de apropriação e construção de formas de pensar, sentir, agir em situações de ensino e atribuir significados a seus componentes, segundo uma matriz ideológica que se constitui social e historicamente". Nossa protagonista transitou sobre as tendências teóricas que historicamente marcaram a educação brasileira; sem dúvida esse movimento foi marcado por um olhar definido, uma percepção do que se deveria perseguir em termos pedagógicos, mas o contexto sóciohistórico-cultural concreto contribuiu de forma significativa para que ela trilhasse um determinado caminho formativo e fosse amealhando certos saberes.

A segunda questão reside na percepção de Francisca acerca dos saberes específicos que envolvem a prática docente no espaço da Educação Infantil. Nesta direção, Gobbi (2010) evidencia a importância de que a prática pedagógica deste nível de ensino privilegie as múltiplas linguagens, para que a criança viva experiências sensíveis e ricas com músicas, artes plásticas, literatura, poesia, etc.; questão presente de forma clara nas DCNEI, pois:

Mais do que nunca, é
preciso possibilitar ao
educando a descoberta de
cores, formas, sabores,
texturas, odores, etc.
diversos daqueles que a
vida moderna lhe
proporciona. Ou, com
mais propriedade, é
preciso educar o seu olhar,
a sua audição, seu tato [...]
para perceberem de modo
mais acurado a realidade
em volta [...] (DUARTE JR.,
2000, p. 29)

Para nós fica claro que ela conhece, reconhece como legítimos, valora e faz uso cotidiano dos saberes necessários para atuação adequada e que garantam práticas educativas diversificadas e de qualidade positiva junto às crianças da Educação Infantil, em concordância com as diretrizes curriculares para este nível de ensino. Em um significativo espaço da carta, Francisca se dedica a descrever uma das atividades que faz com suas crianças, em diferentes turmas/anos letivos:

Uma das minhas propostas de trabalho é escrever uma história por ano com as crianças $e$ editar o livro; ano passado 
escrevemos: 'O Mistério da Beg', que foi uma história de uma sacola que sumiu da sala de aula [...] Este ano estamos escrevendo $o$ livro: 'Era uma casa muito engraçada'; este conta a história de uma chocadeira artesanal que confeccionamos na sala de aula [...] (Excertos da carta de Francisca, 2018).

$\mathrm{O}$ relato detalhado dos dois momentos de trabalho ressaltados - de forma rápida no excerto anterior - é uma leitura agradável e envolvente, que coloca o leitor em contato de forma direta com um momento pedagógico que foi uma experiência evidentemente agradável para todos os sujeitos envolvidos, que muito provavelmente conseguiu provocar aprendizagens significativas nas crianças. Afirmamos isto porque é relatada uma situação em que houve a promoção de diferentes situações lúdicas para discussão das relações e parâmetros éticos que elas devem considerar nas interações sociais; e, uma segunda em que até pintinhos foram levados para a sala de aula para viabilizar formas mais concretas de discutir o fenômeno biológico do nascimento.

Reafirmamos, então, o entendimento de que Francisca tem sedimentada uma identidade profissional docente para atuação na Educação Infantil, uma vez que sua narrativa nos mostrou que suas práticas são organizadas/conduzidas conforme preconizado pelas Diretrizes Curriculares Nacionais para a Educação Infantil: que a especificidade das ações pedagógicas realizadas junto às crianças pequenas está na centralidade das brincadeiras e das relações sociais, assumindo que todas as ações no interior das instituições educativas devem ter caráter relacional e lúdico (RODRIGUES, 2016).

\section{À GUISA DE CONCLUSÃO}

Só podemos olhar o outro e sua história se temos conosco mesmo uma abertura de aprendiz que se observa (se estuda) em sua própria história (WEFFORT, 1995, p. 10).

Assim como apontado na epígrafe, a pesquisa em que estamos envolvidas tem nos colocado na condição de "escutadores"aprendizes de outras e, também, de nossas histórias. Cartas como a de Francisca tem nos permitido conhecer as (trans)formações ocorridas em diferentes trajetórias de vida pessoal e profissional, bem como dialogar com elas em diferentes perspectivas; um exercício que tem nos mostrado que ser professor é "movimento" de construções e reconstruções constantes, determinadas e determinantes de contextos concretos e diversos.

Tal afirmação corrobora o apontamento de Garcia $(2010$, p. 18) sobre como se dá a construção da identidade docente, o qual assegura que esta: "[...] não surge automaticamente como resultado da titulação, ao contrário, é preciso construí-la e modelá-la. E isso requer um processo individual e coletivo de natureza complexa e dinâmica, o que conduz à configuração de representações subjetivas acerca da profissão docente".

Reiteramos que 0 trabalho com narrativas tem nos permitido adentrar em outros - e muitos - "cenários" da profissão docente, que tem paulatinamente nos levado ao entendimento mais claro de que o exercício da docência é paradoxal; pois ao mesmo tempo em que se dá em contexto que exige a interação com inúmeros sujeitos (estudantes, outros profissionais da educação, etc.), é também um trabalho "solitário" e, de certa forma, "isolado" que ocorre não só nas paredes das salas de aula, mas também nas "entranhas" pessoais da(o)s professora(e)s como bem nos mostra a carta de Francisca, corroborando de forma inegável a ideia de que "o professor é uma pessoa", ou nos termos do original: "[...] é impossível separar o eu profissional do eu pessoal [...] A maneira como cada um de nós ensina está diretamente dependente daquilo que somos como pessoa [...]" (NÓVOA, 1992, p. 17, grifos no original). Tomando tais entendimentos como premissas, as reflexões sobre a formação de professores não podem estar centradas apenas nos aspectos técnicos e racionais ligados ao exercício de um saber-fazer profissional.

Tal apontamento remete primeiro a destacar o valor da pesquisa narrativa para "descortinar" a docência com olhares de dentro; bem como para valorizar o professor como profissional/profissão e como o informante mais competente sobre as questões da educação e, principalmente sobre os caminhos de sua 
formação. Nesta direção com bem alerta Passegi (2016, p. 68):

[...] enquanto não se conceber os professores como um adulto em formação, uma pessoa plena de experiências, com capacidade para refletir sobre si, e que tem muito mais para nos contar sobre a escola do que a produção científica atual dispõe sobre o tema, não se avançará, suficientemente, quanto à compreensão das relações que se estabelecem entre formandos e seu processo de formação [...].

A afirmação da autora tem toda relevância ante a riqueza de pistas e provocações trazidas no relato de nossa protagonista, assim como nas outras cartas que temos lido e discutido coletivamente. Todas são tão inquietantes (no sentido positivo) que as reflexões desencadeadas têm sido mais que pertinentes para que 0 grupo (re)pense diferentes questões, e não só as previstas para serem abordadas na proposta inicial de investigação. Dentre as que planejamos estão a construção da identidade e profissionalidade docente e o papel da formação profissional inicial e continuada neste processo; mas extrapolandoas surgiram temas como a socialização escolar; as imagens da escola; as imagens da(s) infância(s); além de um (re)pensar os procedimentos de pesquisa que envolvem recolha e análise de informações junto aos educadores de diferentes níveis e o trabalho de investigação de forma coletiva.

Um segundo ponto diz respeito ao valor das vivências da(o)s colaboradora(e)s do estudo, mas também a nossa, como pesquisadora(e)s. As situações selecionadas para serem divididas conosco por nossa(o)s diferentes colaboradora(e)s evidenciam o apontamento larrosiano de que "[a] experiência é o que nos passa, o que nos acontece, o que nos toca. Não o que se passa, não o que acontece, ou o que toca. [...] (BONDìA, 2002, p. 21). Entendemos que nos são oferecidas exatamente as memórias destas experiências e o contato com as narrativas delas tem nos "tocado" de forma bastante peculiar e profunda, marcando nossas vidas como pesquisadora(e)s e como pessoas.

Outra questão importante que o estudo, de forma geral, tem nos permitido é entender como circulam imagens, representações e estereótipos acerca de alguns conceitos ou situações - que são coletivas e particulares ao mesmo tempo - e trazem marcas significativas para o que se pensa ser a profissão docente. Este "pensar" vai, no limite, alimentar expectativas e imprimir certo tom na ação e discurso cotidiano $\mathrm{da}(\mathrm{o}) \mathrm{s}$ própria(o)s professora(e)s como por exemplo: "É mais fácil trabalhar com crianças pequenas"; "Não é preciso muito conhecimento teórico para ensinar crianças"; "Saber matemática não é tão importante para dar aula nas primeiras séries"; "Na Educação Infantil o repertório tem que ser de brincadeira". No caso da narrativa de Francisca destacamos a sua percepção sobre a Matemática, que fez ela "fugir" para a docência, e mais ainda, para atuação na Educação Infantil.

Enfatizamos que ser professor da educação infantil - ao contrário do que permeia o pensamento do senso comum - exige esforço, estudo e comprometimento em igual medida do que é solicitado na atuação em outros níveis. A natureza dos conteúdos trabalhados com as crianças é diferente, mas isto não torna as tarefas cotidianas menos complexas; pelo contrário, além de todas as outras exigências da docência em geral, ainda é preciso ter muito "fôlego" literalmente - para estar com os pequenos em um ou dois turnos.

A docência junto a crianças pequenas implica atuar no campo não só das aprendizagens relacionadas aos conteúdos das grandes áreas do conhecimento, mas também àquelas que impulsionam o desenvolvimento humano, tais como a motricidade, oralidade, sociabilidade, etc. Reiteramos, não é uma tarefa fácil, tampouco se trata de seguir manuais ou transpor "receitas teóricas" no dia-a-dia. O professor de educação infantil (e de outros níveis) não é um mero executor de ações pré-estabelecidas, bem como seu trabalho não pode estar baseado no senso comum ou somente na própria experiência de vida e/ou livros didáticos. De forma diferente, o profissional da educação infantil deve ser um intelectual, que estuda, pensa e reflete sobre suas ações cotidianas, que investe na sua profissionalidade; implica ter uma sólida formação teórica e forte comprometimento com sua função social. Como assevera Gatti (2010, p. 1 360) “[...] não há consistência em uma 
profissionalização sem a constituição de uma base sólida de conhecimentos e formas de ação". Francisca, nossa protagonista, deixa transparecer ao longo de seus escritos o entendimento desta dimensão da atuação docente, e nos remete a forma poética de Freire (1993, p. 80) evidenciar esta mesma questão:

$$
\begin{aligned}
& \text { Não nasci, porém, } \\
& \text { marcado para ser um } \\
& \text { professor assim. Vim me } \\
& \text { tornando desta forma no } \\
& \text { corpo das tramas, na } \\
& \text { reflexão sobre a ação, na } \\
& \text { observação atenta a } \\
& \text { outras práticas ou à } \\
& \text { prática de outros sujeitos, } \\
& \text { na leitura persistente, } \\
& \text { crítica, de textos teóricos, } \\
& \text { não importa se com eles } \\
& \text { estava de acordo ou não. É } \\
& \text { impossível ensaiarmos } \\
& \text { estar sendo deste modo } \\
& \text { sem uma abertura crítica } \\
& \text { aos diferentes e às } \\
& \text { diferenças, com quem e } \\
& \text { com que é sempre } \\
& \text { provável aprender. (grifos } \\
& \text { no original). }
\end{aligned}
$$

Acreditamos que a trajetória pessoal e profissional de Francisca evidencia esse movimento de construção crítica de sua prática, de si, na percepção do entorno, dos sujeitos pequenos aprendizes - que lida cotidianamente; postura essencial, notadamente na Educação Infantil, posto que, é essencial compreender: quem é a criança, como ela se relaciona com a cultura, de onde ela vem para ser o que ela é hoje, o que posso/devo oferecer para investir no seu potencial. Francisca indica compreender:

[...] a importância do olhar 'olho no olho' das crianças, de todas e de cada uma; de respeitar os tempos e modos próprios dos pequenos, de empregar gestos delicados e consentidos nos momentos de higiene pessoal, alimentação e sono de cada criança. [...] e, ainda, haver o acompanhamento de todas as atividades de exploração do entorno das crianças, pois a presença respeitosa e afetiva dos adultos, não de forma diretiva, interventiva e disciplinar, mas dentro do campo de visão das crianças, garante o apoio e a segurança que as encorajam ao movimento livre e à exploração do seu entorno de forma autônoma. (RODRIGUES, 2016, p. 53).

Parece ser algo óbvio; mas, infelizmente ainda não é... A Educação Infantil, reconhecidamente com caráter educacional tem uma história curta (pouco mais de três décadas); por outro lado, já foram produzidos documentos legais norteadores que indicam claramente como deve ser o trabalho pedagógico nesta etapa de ensino. No entanto, na prática cotidiana, no chamado "chão da escola" e entre as famílias, ainda há falta de clareza sobre quais os conteúdos são ensinados na educação infantil; quais os caminhos metodológicos para desenvolver o trabalho nessa etapa do ensino; bem como quais são os objetivos do trabalho pedagógico e o papel/função do(a) professor(a). Insistimos na busca de superar essas questões que perpassam as discussões na educação para a pequena infância, assim como lutar pela construção da identidade para a docência na Educação Infantil, considerando as especificidades desse trabalho diante da importância de estar atento às necessidades dos bebês e crianças (aprendizes desta etapa de ensino).

Como um delicado e revigorante alento, a narrativa de Francisca apresenta uma professora com o perfil profissional que defendemos; perseguindo e cultivando os saberes que julgamos os mais adequados para atuação na Educação Infantil. Não é nossa intenção romantizar a professora em questão, tampouco tê-la como modelo, pois isso seria incongruente com a defesa já apresentada de que cada profissional é único, "é uma pessoa", que erra e acerta, que se cansa, desanima e tem outras ocupações além da profissão. O que destacamos é sua capacidade de repensar, refletir e reconstruir sua prática profissional a partir disto, um saber que consideramos imprescindível para o pleno exercício da docência.

Ora, um professor de profissão não é somente alguém que aplica 
conhecimentos produzidos por outros, não é somente um agente determinado por mecanismos sociais: é um ator no sentido forte do termo, isto é, um sujeito que assume sua prática a partir dos significados que ele mesmo lhe dá, um sujeito que possui conhecimentos e um saber-fazer provenientes de sua própria atividade e a partir dos quais ele a estrutura e a orienta. (TARDIF, 2014, p. 230).

Francisca mostra-se uma profissional consciente do seu trabalho e profissão, alimenta um lado intelectual que busca conhecimento e (re)pensa sua prática; seleciona e usa os conhecimentos/teorias que lhe são apresentadas como instrumento de análise e (re)planejamento de suas ações didáticas. Ademais, seus relatos corroboram para superarmos a ideia de que ser professor é "dom"; ou ainda, que seja preciso amor - em detrimento da formação, da profissionalização - para seguir na carreira docente.

Ao longo desse trabalho, podemos acompanhar a transformação de Francisca, que no decorrer de sua formação inicial e inserção na carreira docente, vai construindo sua identificação e compromisso com a profissão docente, com um determinado nível de ensino, a preocupação em olhar para si e para a sua prática, corroborando a afirmação de Garcia (2010, p. 19) de que "[...] a identidade profissional é um processo evolutivo de interpretação e reinterpretação de experiências, uma noção que se corresponde com a ideia de que o desenvolvimento do professorado nunca se detém e que se entende como uma aprendizagem ao longo da vida".

A carta de Francisca nos traz estas e outras possibilidades reflexivas, escolhemos destacar as apresentadas no sentido de unir vozes ao movimento de defesa da profissionalização docente, em especial do(a) professor(a) de educação infantil, como o (a) profissional dotado (a) de saberes e experiências, capaz de, através da ludicidade e metodologias específicas para este nível, planejar ações que visem fomentar espaços adequados para desenvolvimento infantil, bem como, que venha a romper e superar, a ideia reducionista do educador infantil como cuidador, que ama/ leva jeito com crianças, como sendo essas características inatas e os pré-requisitos para docência na primeira etapa da educação básica.

Nossa protagonista também se incomoda com alguns dos rumos da Educação Infantil brasileira; mas, por outro lado, assim como nós, acredita que é possível a mudança para melhor...

E assim é o meu trabalho, repleto de surpresas gostosas e novidades, tenho tido muitas alegrias, aprendo e ensino. Todo dia é um pouco de mim que fica, e um pouco dessas vivências que trago comigo. São tantas coisas que não daria para serem escrita em um pequeno relato, seria necessário um livro com muitas páginas, as coisas ruins são na verdade muito poucas, e vejo que na educação infantil temos tido muitos retrocessos sim, mas por outro lado tenho visto avanços muito significativos, principalmente quando vejo a comunidade se articulando com a escola, através [de] pequenas ações que podem fazer a diferença e mudar os rumos da educação no nosso país. (Excerto da carta de Francisca, 2018).

Dessa forma, não poderíamos finalizar nossas reflexões com outra inspiração que não fosse a freireana... O que temos escrito até aqui e o último trecho selecionado da carta de Francisca, nos leva a retomar os saberes que o mestre recifense nos indicou como imprescindíveis para a prática docente: não o amor piegas, mas a amorosidade pelos aprendizes e sua condição como tal; respeito aos saberes dos educandos; ética; criticidade; reflexão crítica sobre a prática; e, por último não menos importante e crucial para o educador da pequena infância: alegria e esperança... Nunca é demais (re)lembrar que:

Não importa com que faixa etária trabalhe o 
educador ou a educadora. O nosso é um trabalho realizado com gente miúda, jovem ou adulta, mas gente em permanente processo de busca. Gente formandose, mudando, crescendo [...] É que lido com gente [...] Se não posso, de um lado, estimular os sonhos impossíveis, não devo, de outro, negar a quem sonha o direito de sonhar. Lido com gente e não com coisas. (FREIRE, 1996, p. 144).

\section{REFERÊNCIAS}

ANGOTTI, Maristela. Educação Infantil: para que, para quem e por quê. In: ANGOTTI, Maristela (org.). Educação Infantil: para que, para quem e por quê? Campinas: Alínea, 2006. p. 15-32.

BAKHTIN, Mikhail. Estética da criação verbal. 2. ed. São Paulo: Martins Fontes, 1997.

BENJAMIN, Walter. Sobre o conceito de história. In: BENJAMIN, W. Obras escolhidas. São Paulo: Brasiliense, 1987. (volume 1).

BONDÍA, Jorge Larrosa. Notas sobre a experiência e o saber da experiência. Tradução João Wanderley Geraldi. Revista Brasileira de Educação, Campinas, n. 19, p. 20-28, jan./fev./mar./abr., 2002. Disponível em: http://www.scielo.br/pdf/rbedu/n19/n19a02.pdf . Acesso em: 28 abr. 2020. DOI:10.1590/S1413-24782002000100003

BRASIL. Lei $\mathrm{n}^{\circ}$. 9.394, de 20 de dezembro de 1996. Estabelece as diretrizes e bases da educação nacional. Diário Oficial da União [da] República Federativa do Brasil, Poder legislativo: Brasília, DF, 23.12.1996, Ano CXXXIV, n. 248, seção 1, p. 27766-27841,1996. Disponível em: http://www.planalto.gov.br/ccivil 03/leis/L9394. htm. Acesso em: 20 ago. 2020.

BRASIL. Ministério da Educação e do Desporto. Coordenadoria de Educação Infantil. Diretrizes Curriculares Nacionais para a Educação Infantil. Brasília: MEC/SEF/COEDI, 2010.

CLANDININ, D. Jean; CONNELLY, F. Michael.
Pesquisa narrativa: experiência e história em pesquisa qualitativa. Uberlândia: EDUFU, 2011.

DUARTE JR., José Francisco. 0 sentido dos sentidos: a educação (do) sensível. 2000. $233 \mathrm{f}$. Tese (Doutorado em Educação) - Universidade Estadual de Campinas, Faculdade de Educação, Campinas, 2000. Disponível em: http://repositorio.unicamp.br/jspui/handle/REPO SIP/253464. Acesso em: 27 ago. 2020.

FERRAROTTI, F. Sobre a autonomia do método biográfico. In: NÓVOA, Antonio; FINGER, M. (org.). $\mathbf{O}$ método (auto)biográfico e a formação. Lisboa: Departamento de Recursos Humanos/ Ministério da Saúde. 1988. p. 17-34.

FREIRE, Paulo. Política e educação. São Paulo: Cortez, 1993.

FREIRE, Paulo. Pedagogia da autonomia: saberes necessários à prática educativa. 44. ed. São Paulo: Paz e Terra, 1996.

GARCÍA, Carlos Marcelo O professor iniciante, a prática pedagógica e o sentido da experiência. Formação Docente, Belo Horizonte, v. 3, n. 3, p. 11-49, ago./dez. 2010. Disponível em: http://formacaodocente.autenticaeditora.com.br . Acesso em: 17 ago. 2020.

GATTI, Bernadete Angelina. Formação de professores no Brasil: características e problemas. Educação e Sociedade, Campinas, v. 31, n. 113, p. 1355 - 1379, out. - dez., 2010. Disponível em: https://www.scielo.br/scielo.php?script=sci artte xt\&pid=S0101-73302010000400016. Acesso em: 17 ago. 2020. DOI:10.1590/S0101-73302010000400016

GOBBI, Márcia. Múltiplas linguagens de meninos e meninas no cotidiano da educação infantil. 2010. Disponível em: http://portal.mec.gov.br/index.php?option=com docman\&view=download\&alias=6678multiplaslinguagens\&category slug=setembro2010-pdf\&ltemid=30192. Acesso em 28 ago. 2020.

GOMES, Alberto. A.; RODRIGUES, Silvia Adriana; SOUZA, Leandro Aparecido. Por que ser professor(a)? Reflexões sobre motivações para o ingresso na carreira docente In: CONGRESSO DE 
EDUCAÇÃO DO CPAN, 4., 2019, Corumbá. Anais on line... Corumbá: CPAN, 2019. v.1. p.1-13

GUIMARÃES, Célia Maria; GARMS, Gilza Maria Zauhy. Currículo para a educação e o cuidado da criança de 0 a 5 anos? Revista Educação, PUCCampinas, Campinas, n. 18, v. 1, p. 19-35, jan./abr., 2013. Disponível em: http://periodicos.puccampinas.edu.br/seer/index.php/reveducacao/ar ticle/view/1895/1723. Acesso em: 20 ago. 2020. DOI:10.24220/2318-0870v18n1a1895

NACARATO, Adair Mendes; MENGALI, Brenda Leme da Silva; PASSOS, Carmem Lúcia Brancaglin. A matemática nos anos iniciais do ensino fundamental: tecendo fios do ensinar e do aprender. 1. reimp. Belo Horizonte: Autêntica, 2011.

NASCIMENTO, M. E. P. Os profissionais da Educação Infantil e a nova Lei de Diretrizes e Bases da

Educação Nacional. In: FARIA, Ana Lúcia Goulart; PALHARES, M. S. (org.). Educação Infantil pósLDB: rumos e desafios. Campinas: Autores Associados, 1999. p. 99-110.

OLIVEIRA, Zilma Moraes Ramos; FERREIRA, Marisa Vasconcelos; BARROS, Joseane Aparecida Bonfim. Formação continuada em educação infantil: a construção de uma agenda de possibilidades. In: GUIMARAES, Célia Maria; REIS, Pedro Guilherme da Rocha dos (org.). Professores e infâncias: estudos e experiências. Araraquara: Junqueira e Marin, 2011. p. 13-28.

NÓVOA, António. Os professores e as histórias de suas vidas. In: NÓVOA, António (org.). Vidas de professores. Porto: Porto Editora, 1992.

PASSEGI, Maria da Conceição. Narrativas da experiência na pesquisa-formação: do sujeito epistêmico ao sujeito biográfico. Roteiro, Joaçaba, v. 41, n. 1, p. 67-86, jan./abr. 2016. Disponível em: https://dialnet.unirioja.es/descarga/articulo/619 5624.pdf. Acesso em: 20 ago. 2020.
DOI:10.18593/r.v41i1.9267

RODRIGUES, Sílvia Adriana. Viajando pela educação da primeiríssima infância: sentidos, crenças e valores que sustentam os saberes e as práticas pedagógicas na/da creche. 2016. 253f. Tese (Doutorado em Educação) - Universidade Estadual Paulista, Faculdade de Ciências e Tecnologia, Presidente Prudente, 2016. Disponível em: https://repositorio.unesp.br/handle/11449/1443 79. Acesso em: 20 ago. 2020.

RODRIGUES, Sílvia Adriana; GOMES, Alberto Albuquerque. Sobre formação, identidade, profissionalização e histórias de vida de professores In: SITRE, 7., 2018, Belo HorizonteMG. Anais on-line... Belo Horizonte: UFMG, 2018. v.1. p. $1-14$.

RODRIGUES, Sílvia Adriana; SAMBUGARI, Márcia Regina do Nascimento Linguagem escrita na Educação Infantil: produções apresentadas na ANPED (2000-2017). Revista Contemporânea de Educação, Rio de Janeiro, v. 13 , n. 28 , set./dez. $2018 . \quad$ Disponível em: https://revistas.ufri.br/index.php/rce/article/vie w/16637/pdf. Acesso em: 20 ago. 2020. DOI:10.20500/rce.v13i26.16637

RODRIGUES, Sílvia Adriana et al. Narrativas sobre os caminhos da profissionalidade docente: a história e os olhares de Ângela. Revista Interfaces Científicas - Educação (ahead of print), 2020.

TARDIF, Maurice. Saberes docentes e formação profissional. 17. ed. Petrópolis: Vozes, 2014.

TARDIF, Maurice; LESSARD, Claude. 0 trabalho docente: elementos para uma teoria da docência como profissão de interações humanas. Petrópolis: Vozes, 1999.

WEFFORT, Madalena Freire. Observação, registro, reflexão. Espaço pedagógico: São Paulo, 1995. 